\title{
MENTES EM REFORMA: O SILENCIAMENTO DA LEI FEDERAL DE N. 10216/01
}

\section{MENTES EN REFORMA: LO SILENCIAMIENTO DE LA LEY FEDERAL No 10216/01}

\section{RESUMO}

\author{
${ }^{1}$ Mellyssa Do Nascimento Costa \\ ${ }^{2}$ Régis André Silveira Limana
}

O presente trabalho tem como objetivo discutir a efetiva aplicação da Reforma Psiquiátrica no Brasil e, em específico, no Estado do Piauí, a partir da Lei Federal de $n^{\circ} 10216 / 01$. Discorre sobre as mudanças dos paradigmas do tratamento de pacientes acometidos de doenças mentais e sobre a tentativa de reestruturação das relações sociais perdidas durante o período de internação em hospitais psiquiátricos por esses indivíduos. Tem também o propósito de debater o que vem mudando na visão da sociedade, a partir da caracterização do portador de transtorno mental não mais como um louco e sim como um paciente que precisa de cuidados. Desse modo, disserta essencialmente sobre a exclusão social da loucura, como ocorreu e como continua acontecendo na sociedade contemporânea. No que tange à importância do estudo proposto, ressalta-se a necessidade de avaliar efetivamente se o processo de inserção social dessas pessoas com transtorno funciona como deveria, se os ex- internos de hospitais psiquiátricos exercem o convívio social, capaz de assegurar o bem-estar global e estimular o exercício pleno de seus direitos civis, políticos e de cidadania. Partindo desses pressupostos, ficou evidente o conflito referente aos direitos humanos, considerando o diploma legal em comento, sendo o sistema de justiça ineficaz no tratamento do portador de transtorno mental. Como metodologia do estudo, foi utilizado o método indutivo e dedutivo.

Palavras-chave: Direitos humanos, Piauí, Reforma psiquiátrica, Residências terapêuticas, Saúde mental

\section{RESUMEN}

El presente trabajo tiene como objetivo discutir la aplicación efectiva de la Reforma Psiquiátrica en Brasil y en particular en el estado de Piauí partiendo de la Ley Federal n.10216/01. Trataremos sobre los cambios de los paradigmas en los tratamientos de pacientes que sufren de enfermedades mentales y en tratar de reestructurar las relaciones sociales que esos individuos perdieron durante el período de hospitalización en esas instituciones psiquiátricas. También es nuestro propósito discutir lo que ha cambiado, en la visión de la sociedad, a partir de la caracterización de los pacientes mentales no como locos sino como pacientes que necesitan cuidados. Este estudio analiza principalmente la exclusión social de la locura, como sucede y como sigue sucediendo en la sociedad contemporánea. En cuanto a la importancia del estudio propuesto, hace hincapié en la necesidad de evaluar de manera efectiva si el proceso de integración social de estas personas con trastorno funciona como debería, si los ex internos de hospitales psiquiátricos ejercen una vida social capaz de asegurar el bienestar s global y fomentar el pleno ejercicio de sus derechos civiles, políticos y de ciudadanos. Con base en estos elementos, es evidente el conflicto de los derechos humanos en relación al estatuto en discusión, demostrando, además, que el sistema de justicia es ineficaz en el tratamiento de la aerolínea de trastorno mental. Hemos adoptado la metodología del estudio, el método inductivo y deductivo.

Palabras-claves: Derechos humanos, Piauí, La reforma psiquiátrica, Casas terapéuticas, Salud mental

\footnotetext{
${ }^{1}$ Mestranda em Direito das Relações Internacionais e da Integração na América Latina pela Universidad de La Empresa - UDE, Montevidéu, (Uruguai). E-maul: tutortreinamento@gmail.com (Brasil)

${ }^{2}$ Mestrando em Direito das Relações Internacionais pela pela Universidad de La Empresa UDE, Montevidéu, (Uruguai). Policial Rodoviário Federal lotado na 9a Superintendência da Polícia Rodoviária Federal, Porto Alegre, RS. (Brasil). E-mail: tutortreinamento@gmail.com
} 


\section{INTRODUÇÃO}

Com a intenção de gerar reflexões acerca da Reforma Psiquiátrica, que visa uma mudança de paradigma no tratamento dos portadores de doença mental, convertendo o modelo hospitalicêntrico manicomial em tratamento extra-hospitalar, a partir das lentes dos direitos humanos, é nosso objetivo proporcionar uma análise crítica do que vem sendo feito para a mudança gradual das concepções que cerca o tema. É nosso intuito também, proporcionar um material de registro da situação atual de atendimento à saúde mental, com foco no Estado do Piauí, mas levando em consideração a aplicabilidade da lei em todo país, pautado nos direitos fundamentais previstos na Constituição Federal.

A temática alcança a dimensão mais ampla da esfera social, com base nos efeitos da própria visão que os sujeitos sociais têm sobre a loucura. Todos os ex-internos de hospitais psiquiátricos sofreram maus tratos e, em consequência disso, tiveram sua dignidade humana violada, ao longo de anos de internações psiquiátricas. Alguns pacientes com tais doenças mentais chegaram ainda crianças aos hospitais e perderam completamente os vínculos familiares e a convivência social. Historicamente, em todo o Brasil e, mais especificamente, no Piauí, portadores de transtornos mentais sofreram com incontáveis manifestações de preconceito e segregação, algo que pode ser visto ainda nos dias atuais ${ }^{1}$.

Com a pretensão de reintegrar os pacientes com transtornos mentais à cidadania, foi instituída a Lei $\mathrm{n}^{\mathrm{o}}$ 10.216/01, que concomitou em grandes passos para a construção da Reforma Psiquiátrica. Entretanto, o país ainda precisa avançar para que, de fato, a lei seja aplicada em toda a rede de atendimento psiquiátrico. Nessa perspectiva, o trabalho tem relevância, devido a sua nova política de Reforma Psiquiátrica.

Para que sejam melhor compreendidas as movimentações reformistas no contexto nacional e estadual (Piauí), serão aprofundados os principais aspectos que caracterizaram a implantação da política de saúde mental, a partir dos acontecimentos que marcaram a história dessas pessoas que estiveram internadas em hospitais psiquiátricos e, que atualmente, em sua minoria, estão em residências terapêuticas.

Em relação à abordagem do tema reformista, ele oferece a possibilidade de uma discussão sobre alguns pontos da realidade, pois intenta gerar discussões e reflexões a respeito de problemas apresentados ao decorrer do nosso estudo, envolvendo situações de preconceito,

1 Constatações realizadas a partir de estudos dentro do Hospital Psiquiátrico Areolino de Abreu, em Teresina PI. 
gerados a partir da crença brasileira na figura do louco como portador de perigo. Para tanto, o desenvolvimento deste trabalho tem a finalidade de aumentar e gerar conhecimento sobre a área estudada, além de contribuir com material científico, possibilitando que a comunidade acadêmica tenha informações adicionais para estudos posteriores dentro da temática. A pesquisa propõe ainda uma reflexão sobre a reabilitação e resgate da cidadania dos pacientes portadores de transtornos mentais, bem como a valorização desses sujeitos.

A sociedade sempre teve dificuldade em lidar com as diferenças. Na psiquiatria, o tratamento da loucura, por vezes, foi baseado na intolerância frente aos comportamentos dos doentes mentais, tendo no cárcere dos indivíduos uma opção para afugentar o diferente e “proteger a sociedade". Em detrimento disso, a Lei no 10.216, de 2001, legitima a Reforma Psiquiátrica no Brasil. O Projeto de Lei $n^{\circ} 3.657 / 89$, que a antecedeu, representou a justa percepção sobre a necessidade urgente de reformar a assistência psiquiátrica e de lutar pela garantia dos direitos de cidadania dos doentes mentais.

No que diz respeito às tratativas da lei vigente, está a garantia dos direitos básicos do doente mental, inclusive o de ter acesso aos melhores recursos, diagnósticos e serviços terapêuticos disponíveis numa rede de saúde diversificada. A lei ressalta ainda, a necessidade de políticas específicas de desospitalização.

Não há, neste artigo, a pretensão de simplificar ou polemizar a aplicabilidade da internação no tratamento das doenças mentais. Entendemos que a discussão quanto à sua aplicabilidade é complexa e esbarra também em sua representação social, cultural e econômica. É notório que a partir de um modelo centrado quase que exclusivamente na internação em hospitais psiquiátricos, no decorrer de pouco mais de uma década, está sendo possível, de forma gradual, redirecionar a saúde mental para uma rede de cuidados extrahospitalares. Os efeitos dessa mudança começam a ser visíveis, com a sensível ampliação das possibilidades de acesso ao tratamento em saúde mental, porém, falta alcançar a dimensão mais ampla da esfera social, pretendendo que se modifique a percepção acerca da loucura.

A mudança prevista no modelo reformista ainda caminha a passos lentos e é sentida no cotidiano de trabalho nos Centros de Atenção Psicossocial (CAPS), e nos demais serviços oferecidos pela rede de saúde, prevista pela Reforma Psiquiátrica, regulamentada pela Lei $\mathrm{n}^{\circ}$ $10.216 / 01$.

\section{REFORMA PSIQUIÁTRICA NO BRASIL}


Para que se compreenda como a Reforma Psiquiátrica se instaurou no Brasil, é necessário que façamos um percurso no contexto histórico reformista, com a pretensão de perceber seu reflexo na contemporaneidade. Liderado pelo psiquiatra Franco Basaglia, o movimento de luta antimanicomial iniciou-se na Itália em meados da década de 1960, visando à humanização do tratamento psiquiátrico, bem como suas condições de funcionamento (profissional, sanitária, dentre outros). Mais tarde, em 1973, a luta foi intitulada de "Psiquiatria Democrática". Nesse mesmo ano, a Organização Mundial da Saúde (OMS) credenciou o serviço psiquiátrico desenvolvido por Basaglia, como referência para reformulação de assistência em saúde mental, modelo no qual o Brasil se inspirou para a sua reforma psiquiátrica.

\begin{abstract}
A loucura tem sido encontrada nas mais diversas sociedades em variadas épocas, partindo desse contexto, entendemos que, a estas manifestações há uma freqüente identificação do indivíduo louco como o diferente, o outro, aquele que não se encontra na esfera do aceitável e não se mostra capaz de se manter na coletividade como os indivíduos tidos como normais, embora sua circulação tenha sido relativamente tolerada em sociedades pré-capitalistas. (MACEDO, 2006, p. 1).
\end{abstract}

Baseado no modelo reformista proposto por Basaglia na Itália, a discussão chega ao Brasil motivada pela necessidade de humanização do tratamento de pacientes com transtornos mentais, na década de 1970. Segundo Tenório (2001), nesse período, já foram registradas as primeiras denúncias de maus tratos, abandono e violência dentro dos hospícios, comprovando o comportamento abusivo e os desvios promovidos pela psiquiatria. Muitas dessas denúncias foram feitas pelo primeiro movimento considerado antimanicomial: o Movimento dos Trabalhadores em Saúde Mental (MTSM). Na década de 80, o MTSM propõe reformulações no sistema de saúde mental vigente até hoje. Entretanto, ainda na perspectiva de Tenório (2001), não existe ainda nenhum tipo de discussão mais aprofundada e embasada acerca dos direitos dos pacientes, e sua assistência continua bastante precária.

É válido destacar que a primeira grande revolução aconteceu em 1987, quando ocorreu a I Conferência de Saúde Mental. Esse evento representou o marco inicial da luta antimanicomial, que teve como lema "Por uma sociedade sem manicômios". A conferência foi marcada principalmente pela participação das instituições, pacientes e seus familiares, visto que, para alcançar anseios dos pacientes com transtorno mental, nada mais plausível do que ouvi-los. Em consonância com esse entendimento, Tenório (2001, p. 37) afirma que essa 
luta “[...] trata-se de convocar a sociedade para discutir e reconstruir sua relação com o louco e a loucura".

Ao tratar sobre a reforma psiquiátrica no Brasil, Tenório (2001) cita que o resultado das lutas dos movimentos antimanicomiais ocorreu em 1989, com a propositura na Câmara Federal do Projeto de Lei n 3.657 pelo deputado Paulo Delgado. O projeto tinha como proposta a extinção progressiva dos manicômios e sua substituição por outros recursos assistenciais. Nesse momento, deu-se o começo das lutas do movimento da Reforma Psiquiátrica nos campos legislativo e jurídico. Em 1991, a Portaria nº 189 do Ministério da Saúde impôs um rigor maior às internações psiquiátricas e implementou, no Sistema Único de Saúde (SUS), os procedimentos em saúde mental realizados nos CAPS e nos Núcleos de Assistência Psicossocial (NAPS). No ano seguinte, a Portaria $n^{\circ} 224$ regulamentou o funcionamento desses serviços, seguindo diretrizes de atenção integral, regionalizada e multiprofissional.

Referente ao percurso da reforma psiquiátrica antimanicomial no Brasil, Aluísio Ferreira de Lima (2010) traça um panorama explicativo:

O primeiro momento da reforma psiquiátrica brasileira, que toma como marco inaugural a fundação, em 1978, do Movimento de Trabalhadores em Saúde Mental (MTSM), foi o instante de questionamento da política de saúde mental desenvolvida no Brasil, que embora desde 1961 preconizasse os serviços de tratamento em saúde mental situados nos territórios continuava financiando massivamente os asilos privados desde 1946, instituições que, por sua vez, sofriam várias críticas por serem espaços de segregação pessoal e aniquilação subjetiva [...] Assume-se, com o questionamento da política de saúde mental desse período, o desafio à superação dessas instituições que eram hegemônicas no país. As discussões estavam voltadas para a garantia de direitos dos pacientes, o aperfeiçoamento e universalização dos instrumentos utilizados até então, ou seja, o direito à saúde como questão político-social [...]. O segundo momento da reforma psiquiátrica brasileira, por sua vez, se concretizou com criação do Movimento de Luta Antimanicomial, que se espalhou pelo país com a sustentação de um discurso alternativo ao sistema manicomial a partir da invenção de novos dispositivos e tecnologias de cuidado, substituindo a clínica fechada por instrumentos abertos, diversificados, de natureza comunitária, que garantiriam a desinstitucionalização. [...] Na virada do século $\mathrm{XX}$, presencia-se o terceiro momento da reforma psiquiátrica, possibilitado pela paulatina entrada de militantes do movimento antimanicomial no interior dos aparelhos de Estado. Com a aprovação da Lei $n^{\circ} 10.216$, de 6 de abril de 2001, que contemplava a Declaração de Caracas de 14 de novembro de 1990, o que até então era uma proposição alternativa à política de saúde mental desenvolvida, transforma-se, nesse momento, em uma política de Estado. Em outras palavras, aquilo que era oposição ao sistema tornou-se posição do sistema, apoiada em uma lei federal que organizaria a saúde mental no país e concretizaria uma complexa e 
sistemática política pública embasada em leis, portarias ministeriais, leis municipais e estaduais, etc. (LIMA, 2010, p. 169-170).

Nos dias atuais, sabe-se que, apesar de inúmeras leis e portarias do Ministério da Saúde tratarem da necessidade de atendimentos extra-hospitalares, ainda não é essa a realidade existente no nosso país. O número de residentes em hospitais psiquiátricos continua sendo bastante significativo, tornando insuficiente a implementação dos serviços substitutivos a exemplo do CAPS. Desse modo, a instituição psiquiátrica ainda é o principal meio de exclusão, apesar da criação de serviços alternativos supracitados.

Em complemento ao exposto, é válido citar um trecho do relatório de 2005 da Conferência Regional de Reforma dos Serviços de Saúde Mental do Ministério da Saúde (2005, p. 6), o qual versa sobre a Reforma Psiquiátrica:

[...] é processo político e social complexo, composto de atores, instituições e forças de diferentes origens, e que incide em territórios diversos, nos governos federal, estadual e municipal, nas universidades, no mercado dos serviços de saúde, nos conselhos profissionais, nas associações de pessoas com transtornos mentais e de seus familiares, nos movimentos sociais, e nos territórios do imaginário social e da opinião pública. Compreendida como um conjunto de transformações de práticas, saberes, valores culturais e sociais, é no cotidiano da vida das instituições, dos serviços e das relações interpessoais que o processo da Reforma Psiquiátrica avança, marcado por impasses, tensões, conflitos e desafios.

No mesmo contexto, Birman (1992) afirma que qualquer reforma psiquiátrica radical deve começar pelo reconhecimento do paradoxo da cidadania, para o autor:

A reforma psiquiátrica e o reconhecimento efetivo da cidadania para os loucos implicam na constatação de que estes não têm qualquer dívida para com nossa razão científica e tecnológica, de que não existe absolutamente nos loucos nenhuma falta a ser preenchida para se transformarem em sujeitos da razão e da vontade. (BIRMAN 1992, p. 88).

Tecendo uma crítica aos métodos utilizados dentro da saúde mental, Szasz (1978) vai dezer que:

Em minha opinião, a saúde mental [...] não pode ser melhorada por slogans, medicamentos, centros comunitários de saúde mental, ou mesmo bilhões de dólares gastos numa "guerra contra a doença mental". O principal problema da psiquiatria foi, e continua sendo, o da violência: a violência ameaçada e temida do "louco" e a violência contrária e real da sociedade contra ele. Disso resultam a desumanização, a opressão e a perseguição do cidadão estigmatizado como, mentalmente doente. (SZASZ, 1978, p. 17). 


\subsection{Caso Damião Ximenes}

Falaremos aqui do caso de repercussão internacional que marcou a história da Reforma Psiquiátrica no país, conhecido como "caso Damião Ximenes". Achamos importante discorrer sobre esse fato, por se tratar de um caso de extrema importância para o cumprimento da Lei $\mathrm{n}^{\circ}$ 10.216/01, em que o Brasil foi processado e condenado na Corte Interamericana de Direitos Humanos da Organização dos Estados Americanos (OEA), da qual o Brasil é signatário, por não cumprir os Direitos Humanos. O caso citado foi referente a um paciente portador de doença mental que sofreu maus tratos em uma clínica psiquiátrica até chegar a óbito.

No que se refere ao Direito Internacional dos Direitos Humanos, Queiroz (2006) enuncia que:

[...] o Direito Internacional dos Direitos Humanos tem por objetivo concretizar, plenamente, a eficácia dos direitos humanos fundamentais dos quais o homem é dotado, que, inerentes à sua personalidade, são reconhecidos pelo Direito Internacional Público, que os coloca sob sua garantia. (QUEIROZ, 2006, p. 63).

O país foi julgado e sentenciado pela morte de Damião Ximenes Lopes na Casa de Repouso Guararapes, em Sobral, Ceará, em 1999, por ter violado quatro artigos da Convenção Americana: os direitos à vida, à integridade física, às garantias judiciais e à proteção judicial. A família de Damião Ximenes deu entrada na Corte Interamericana de Direitos Humanos devido à morosidade e descaso da Justiça brasileira com o caso.

Achamos pertinente citar determinados trechos acerca da sentença da Corte Interamericana de Direitos Humanos:

\section{[...] XII}

PONTOS RESOLUTIVOS

262. Portanto, A CORTE, DECIDE, Por unanimidade,

1. Admitir o reconhecimento parcial de responsabilidade internacional efetuado pelo Estado pela violação dos direitos à vida e à integridade pessoal consagrados nos artigos 4.1 e 5.1 e 5.2 da Convenção Americana, em relação com a obrigação geral de respeitar e garantir os direitos estabelecida no artigo 1.1 desse tratado, em detrimento do senhor Damião Ximenes Lopes, nos termos dos parágrafos 61 a 81 da presente Sentença.

DECLARA, Por unanimidade, que

2. O Estado violou em detrimento do senhor Damião Ximenes Lopes, tal como o reconheceu, os direitos à vida e à integridade pessoal consagrados 
nos artigos 4.1 e 5.1 e 5.2 da Convenção Americana, em relação com a obrigação geral de respeitar e garantir os direitos estabelecida no artigo 1.1 desse tratado, nos termos dos parágrafos 119 a 150 da presente Sentença.

$[\ldots]$

E DISPÕE, Por unanimidade, que:

6. O Estado deve garantir, em um prazo razoável, que o processo interno destinado a investigar e sancionar os responsáveis pelos fatos deste caso surta seus devidos efeitos, nos termos dos parágrafos 245 a 248 da presente Sentença.

[...]

8. O Estado deve continuar a desenvolver um programa de formação e capacitação para o pessoal médico, de psiquiatria e psicologia, de enfermagem e auxiliares de enfermagem e para todas as pessoas vinculadas ao atendimento de saúde mental, em especial sobre os princípios que devem reger o trato das pessoas portadoras de deficiência mental, conforme os padrões internacionais sobre a matéria e aqueles dispostos nesta Sentença, nos termos do parágrafo 250 da presente Sentença.

[...]

12. Supervisionará o cumprimento íntegro desta Sentença e dará por concluído este caso uma vez que o Estado tenha dado cabal cumprimento ao

disposto nesta Sentença. No prazo de um ano, contado a partir da notificação desta Sentença, o Estado deverá apresentar à Corte relatório sobre as medidas adotadas para o seu cumprimento.

[...].

Essa decisão nos leva a refletir sobre como o país tem tratado o portador de doença mental. O mais importante dessa condenação é a reflexão de como o país pode “[...] pagar a dívida" com essa parcela da sociedade que ainda sofre preconceito com o estigma da loucura e como se pode melhorar o tratamento disponibilizado para os mesmos. O fato é que a legitimação de uma democracia se faz ante a proteção dos direitos humanos, e a nossa Constituição Federal consagra como um dos seus fundamentos a dignidade da pessoa humana, sem distinção alguma de raça, sexo, credo e suas condições de saúde, sejam elas mentais ou físicas.

Subsidiando tal reflexão, Paulo Delgado (2010) ressalta ainda que:

A sociedade cria e recria normas para definir o que rejeita e consagra. Faz-se progressista na área da saúde por atitudes, mais do que por atos. Assim, inscrever o doente mental na história da saúde pública, aumentando sua aceitação social, diminuindo o estigma da periculosidade e incapacidade civil absoluta, contribui para elevar o padrão de civilidade da vida quotidiana. A doença mental não é contagiosa, dispensa isolamento. Não pode ser compreendida orgânica apaziguada só pela quimioterapia e os remédios. Claro, é o avanço da medicina e da farmacologia que permite a reinserção social, convivência, restituindo o indivíduo, sua alma e desejos, ao mundo dos vivos. A medicina não deve ser carceral para ampliar a solidão moral do paciente como se sua doença criasse para ele um mundo de não direito. (DELGADO, 2010, p. 25). 


\subsection{Reforma Psiquiátrica no Piauí e as Residências Terapêuticas}

Diante do que foi discutido nos tópicos anteriores, trataremos sobre a aplicabilidade da Reforma Psiquiátrica no Estado do Piauí, nosso foco de estudo, e sobre a implementação de serviços substitutivos extra-hospitalares, em especial, as Residências Terapêuticas. No intuito de cumprir o corpo da Lei $n^{\circ} 10.216 / 01$, o Ministério da Saúde implantou algumas portarias normativas, dentre elas, encontra-se a Portaria $\mathrm{n}^{\circ} 224$, de 1992, que traz regras claras a respeito do atendimento para os portadores de doenças mentais, com serviços oferecidos no que tange ao: Atendimento ambulatorial e de saúde mental, Centros e Núcleos de Atenção Psicossocial (CAPS/NAPS), Hospital-Dia, Serviço de urgência psiquiátrica em hospital-geral, leito psiquiátrico em hospital-geral, e, ainda, padrões mínimos para o atendimento nos hospitais psiquiátricos, para que seja totalmente restabelecido o convívio em sociedade desse paciente. Outra portaria que merece ser frisada é a $n^{\circ} 106$, de 11 de fevereiro de 2000, que criou os Serviços Residenciais Terapêuticos.

Os Serviços Residenciais Terapêuticos, também conhecidos como Residências Terapêuticas, são casas, locais de moradia, destinadas a pessoas com transtornos mentais que permaneceram em longas internações psiquiátricas e que são impossibilitadas de retornar às suas famílias de origem. Esses dispositivos são centrais no processo de desinstitucionalização e reinserção social dos egressos dos hospitais psiquiátricos. Em todo o território nacional, existem mais de 470 Residências Terapêuticas, segundo o Ministério da Saúde. No Piauí, há quatro residências desse tipo, com 22 moradores.

Essas residências são casas comuns sem identificação (placa informativa ou pintura), que são alugadas normalmente em imobiliárias e mantidas pelo governo. No estado piauiense, convivem até seis ex-internos que moravam no hospital psiquiátrico Areolino de Abreu. Em cada residência, os residentes são assistidos por uma coordenadora e duas cuidadoras, que fazem trabalhos domésticos em revezamento de turnos.

Ao visitarmos essas quatro residências do Estado do Piauí, constatou-se que, os moradores são pessoas que, literalmente, perderam sua identidade pessoal ao longo de tantos anos morando no hospital psiquiátrico e que o processo de ressocialização e a devolução da cidadania ocorrem de forma lenta e progressiva.

É válido exemplificar que alguns moradores das residências terapêuticas do Piauí ainda não se acostumaram a dormir em suas camas, e continuam dormindo no chão, por terem adquirido tal hábito dentro do hospital. Outros, mesmo se adaptando às suas camas, continuam escondendo o chileno atrás do travesseiro antes de dormir por ter sido, durante um 
longo período de tempo, seu único bem pessoal. Muitas vezes, os chinelos serviam como elemento de diferenciação, uma vez que vestiam uniforme, nas cores "verde hospício" ou "azul manicômio".

No Piauí, apenas um hospital público psiquiátrico atende a uma grande demanda. Nos antigos internos do Areolino de Abreu, ainda são muitas as lembranças de uma época sombria, em que os portadores de doença mental eram condenados a uma vida desumana e isolada. Apesar do Movimento Reformista ter surgido efetivamente na década de 70, no Brasil, no Estado do Piauí, ele surgiu somente na década de 90, em atendimento às exigências das portarias do Ministério da Saúde.

\section{JUSTIÇA CRIMINAL X DIREITOS HUMANOS}

A justiça criminal atualmente tem agido contrariamente aos direitos e garantias fundamentais previstos na Constituição Federal, em razão de sua ineficácia. Os juízes, promotores e defensores ainda desconhecem ou se recusam a reconhecer os preceitos da Lei $\mathrm{n}^{\mathrm{o}} 10.216 / 01$, que trata sobre a Reforma Psiquiátrica. De todas as modificações ocorridas e em andamento na Reforma Psiquiátrica no Brasil, o que pretendemos tratar, em maior destaque, é da necessidade de mudança na forma de compreender o fenômeno "loucura" pela sociedade, pelos profissionais da saúde e, especialmente, pelos operadores do Direito.

No que diz respeito à internação, ponto em que conota certa polêmica no tratamento ou não do paciente com transtorno mental, Foucault tece uma crítica a este modelo, ao afirmar que:

Na história do desatino, ela [a internação] designa um momento decisivo: o momento social em que a loucura é percebida no horizonte social da pobreza, da incapacidade para o trabalho, da impossibilidade de integrar-se no grupo; o momento em que começa a inserir-se no texto dos problemas da cidade. As novas significações atribuídas à pobreza, a importância dada à obrigação do trabalho e todos os valores éticos a ele ligados determinam a experiência que se faz da loucura e modificam-lhe o sentido. (FOUCAULT, 2004, p. 78).

A reforma versa sobre a internação em alguns artigos. No seu art. $4^{\circ}$, caput: "A internação, em qualquer de suas modalidades, só será indicada quando os recursos extrahospitalares se mostrarem insuficientes". Já no art. $6^{\circ}$, parágrafo único, inciso III, diz que "A internação psiquiátrica somente será realizada mediante laudo médico circunstanciado que caracterize os seus motivos". 
Entretanto, os magistrados continuam emitindo liminares determinando a internação compulsória, a seu livre convencimento, sem o laudo de um psiquiatra exigido pela Lei $\mathrm{n}^{\circ}$ 10.216/01. Enquanto isso, a promotoria e a defensoria nada ou pouco fazem nesse sentido. Ainda se faz necessário destacar que, além de ocorrer a ilegalidade na internação, muitas vezes, o paciente recebe alta médica do hospital psiquiátrico, mas fica impedido de deixar o hospital por força de ordem judicial, que, devido à burocratização inerente do Judiciário, não acompanha os processos como deveria ou nega a desospitalização do paciente, fazendo com que o interno continue internado por muito tempo, ultrapassando o seu período de permanência, ou, porque não dizer, sem a necessidade, muitas vezes, de permanecer internado. Nesse sentido, o juiz só poderá determinar a internação do portador de doença mental munido de um laudo médico circunstanciado, não havendo recursos extra-hospitalares suficientes. Nesse prisma, a internação compulsória, em muitos casos, fere diretamente o artigo $5^{\circ}$ da Constituição Federal Brasileira.

Com as contribuições a partir do advento da Lei da Reforma Psiquiátrica, podemos destacar a equiparação do doente mental ao não doente, conforme o $\operatorname{art.~} 1^{\circ}$ :

Os direitos e a proteção das pessoas acometidas de transtorno mental, de que trata esta Lei, são assegurados sem qualquer forma de discriminação quanto à raça, cor, sexo, orientação sexual, religião, opção política, nacionalidade, idade, família, recursos econômicos e ao grau de gravidade ou tempo de evolução de seu transtorno, ou qualquer outra.

É necessário que se faça uma atualização extremamente clara e didática da Lei ${ }^{\circ}$ 10.216/01 dirigida aos operadores de direito, em especial, magistrados, promotores e defensores, para que haja eficácia e utilidade desse instrumento legal na orientação do ofício diário dos mesmos.

$\mathrm{O}$ artigo $2^{\circ}$, por sua vez, estipula o dever de informação dos direitos estabelecidos para os portadores de doença mental nos estabelecimentos especializados. Em seu parágrafo único, são situados tais direitos, que se referem às condições de realização do tratamento e riscos possíveis de serem sofridos. Desta forma, o próprio tratamento pode ser considerado um risco para a integridade da pessoa, ocasião em que esta possui direito de conhecê- los e dispor sua opinião sobre eles. (BRITTO, 2004, p. 210).

Em continuidade a essa discussão, Souto (2007) destaca que:

Os parágrafos do artigo $4^{\circ}$ regulamentam, por sua vez, a internação e determinam que o tratamento deve primar pela reinserção social do paciente 
e oferecer assistência integral através de uma equipe multidisciplinar. A humanização do atendimento é regra clara, sendo vedada a internação em instituições com características asilares e que não assegurem ao paciente os direitos humanos enumerados no $\S$ único do art. $2^{\circ}$ da Lei 10.216/01. Assim, conforme a norma analisada, resta evidente que o paciente não deve ser alvo de uma estrutura de negação dos direitos humanos. O Estado, nesse prisma, tem limites na imposição de sanção penal a inimputáveis. (SOUTO, 2007, p. $582)$.

A relação do Judiciário, Ministério Público, Defensoria Pública, OAB, CNJ e a aplicação da Lei no 10.216/01, referente à garantia dos Direitos Humanos, vêm evidenciando a falta de compartilhamento das mesmas premissas, embora todos tenham um cenário comum que é a Constituição Federal e, principalmente, a saúde como direito. Temos muito a caminhar para a efetiva aplicabilidade da Lei da Reforma Psiquiátrica. Desse modo, ao passo que a Justiça reconheceu normativamente a da Lei $n^{\circ}$ 10.216/01, infelizmente, em muitos casos, deixa a desejar na prática por desinformação ou desatualização, continuando a internar compulsoriamente doentes mentais sem observância aos direitos humanos conquistados pela lei reformista, que, na maioria das vezes, não se faz necessária. Assim, a maioria dos casos possui problemas de fundo social, de segurança pública, entre outros.

\subsection{Medida de Segurança e a Lei no 10.216/01}

Com o advento da Reforma Psiquiátrica, faz-se necessária uma reformulação do instituto da Medida de Segurança no Brasil, a partir de sua aplicabilidade. Ela tem como principal objetivo o caráter preventivo, mas, na maioria dos casos, não se cumpre sua principal premissa, pois retira do infrator, portador de transtorno mental, a condição de sujeito de direitos, ferindo sua dignidade como pessoa e os Direitos Humanos fundamentados na Constituição Federal.

De acordo com o artigo 26 do Código Penal:

Art. 26 É isento de pena o agente que, por doença mental ou desenvolvimento mental incompleto ou retardado, era, ao tempo da ação ou da omissão, inteiramente incapaz de entender o caráter ilícito do fato ou de determinar-se de acordo com esse entendimento.

Parágrafo único - A pena pode ser reduzida de um a dois terços, se o agente, em virtude de perturbação de saúde mental ou por desenvolvimento mental incompleto ou retardado não era inteiramente capaz de entender o caráter ilícito do fato ou de determinar-se de acordo com esse entendimento. 
As medidas de segurança, na maioria dos casos, segregam e estigmatizam o louco infrator como "indivíduos extremamente perigosos":

[...] a diferença entre pena e medida de segurança. Enquanto aquela teria caráter repressivo, condicionada principalmente pelo delito cometido, esta seria uma medida de "prevenção" e "assistência social", e seria estabelecida em conformidade com a periculosidade do indivíduo em questão. Por isso, não possuiria duração determinada, prolongando-se enquanto durasse o estado perigoso, como estabelecia o artigo 88 . Nesse sentido, as medidas de segurança representavam mais um avanço da sobreposição do princípio da culpabilidade pelo da periculosidade. (FERLA, 2005, p. 319).

Sobre o assunto, é relevante conhecer o pensamento de Jacobina (2008), que, segundo ele:

Da forma com que está prevista no nosso direito atualmente, ela seria um tratamento cuja alta não se daria em razão pura e simples da recuperação do paciente, mas pela sua submissão à perícia de cessação de periculosidade periódica, submetida ao juiz, que passaria, sem ser médico, a ter o poder clínico de considerar o paciente curado, mesmo quando a própria ciência discute se é possível falar em cura da loucura. Seria, além do mais, um tratamento imposto no âmbito de um processo penal, por um juiz com competência penal, mas sob um discurso sanitarista. Há, por conseguinte, um completo descompasso entre aquilo que se considera como medida de segurança no direito penal e aquilo que hoje se considera como medida terapêutica para pacientes com transtornos mentais, na ciência e no próprio direito sanitário. (JACOBINA, 2008, p. 133).

A atual aplicação das Medidas de Segurança no Brasil mostra-se incompatível com a Lei $n^{\circ} 10.216 / 01$, no que se refere à medida de segurança como internação compulsória, em seus art. $6^{\circ}$, III, e $9^{\circ}$. As propostas esculpidas no diploma legal propõem uma releitura do Código Penal e da Lei de Execução Penal. E essa mudança de paradigma é o grande desafio para os operadores de Direito. Podemos constatar também que essa incompatibilidade pouco tem sido diminuída com o passar dos anos da instituição da lei reformista.

A Lei da Reforma Psiquiátrica, $n^{\circ}$ 10.216/01, baseada principalmente em uma ideia desospitalar e reformista implica diretamente na medida de segurança prevista no Brasil. Sobre o tema, pode-se enumerar, nas palavras de Paulo Jacobina (2006):

a) Abordagem interdisciplinar da saúde mental, sem prevalência de um profissional sobre o outro. b) Negativa do caráter terapêutico do internamento. c) Respeito pleno da especificidade do paciente, e da natureza plenamente humana da sua psicose. d) Discussão do conceito de "cura", não mais como "devolução" ao paciente de uma "sanidade perdida", mas como 
trabalho permanente de construção de um "sujeito" onde parece existir apenas um "objeto" de intervenção terapêutica. e) A denúncia das estruturas tradicionais como estruturas de repressão e exclusão. f) A não neutralidade da ciência. g) $\mathrm{O}$ reconhecimento da inter-relação estreita entre as estruturas psiquiátricas tradicionais e o aparato jurídico-policial. (JACOBINA, 2006, p. 17).

Diante do que foi exposto, o que acontece na prática é a efetivação do preconceito sobre a periculosidade da loucura. Os ditos loucos continuam, em sua maioria, isolados socialmente, no caso da medida de segurança, ao invés de receber um tratamento adequado. $\mathrm{O}$ processo é inverso; o paciente é internado, em vez de fornecer tratamento adequado e ressocializador, os transforma em "lixos humanos" que, com o passar dos anos, perdem sua personalidade e se transformam em peças de hospitais. Em muitas cidades brasileiras, os pacientes ainda são submetidos a "tratamento" desumano. A justiça criminal, em oposição a um modelo terapêutico adequado, aplica uma pena, chegando a ser mais severa do que a pena de reclusão do sistema prisional, pois, muitas vezes, ultrapassa os 30 anos.

\subsection{Experiência de Sucesso: PAILI}

Há muitas discussões em relação à necessidade de alteração legislativa para a efetiva aplicabilidade da Lei $\mathrm{n}^{\mathrm{o}}$ 10.216/01, o que tem gerado conflitos entre a justiça criminal e os Direitos Humanos previstos na Lei da Reforma Psiquiátrica. Entendemos que não há necessidade de tal situação conflituosa entre as duas instâncias, tendo em vista que é totalmente possível disponibilizarem um tratamento mais humanitário para os portadores de doença mental. Exemplo disso é o Programa de Atenção integral ao Louco Infrator (PAILI), que funciona com excelência em Goiás, principalmente na cidade de Goiânia.

Consideramos que o Programa é a melhor experiência positiva na área de saúde mental disponibilizada aos infratores do Código Penal no Brasil. O PAILI é desenvolvido por uma parceria coordenada e idealizada pelo Promotor de Justiça Haroldo Caetano da Silva (2010), premiado pelo instituto Innovare, na VI edição, no ano de 2009, na categoria Ministério Público, pela criação do Programa. O resultado do programa tem sido uma nova política de assistência ao louco infrator, provando ser possível aplicar a Medida de Segurança de forma ressocializadora e com tratamento adequado aos pacientes com transtornos mentais.

Sobre o Programa de Atenção integral ao Louco Infrator (PAILI), Haroldo Caetano da Silva (2010) explica que: 
Com autonomia para ministrar o tratamento nesse modelo inovador, os médicos e as equipes psicossociais das unidades de serviços abertos e das clínicas conveniadas ao SUS determinam e colocam em prática a melhor terapêutica, acompanhados de perto pelos profissionais do PAILI, cuja atuação é marcada pelo contato contínuo com os familiares dos pacientes e pela interlocução e integração com todo o sistema de saúde mental, especialmente os Centros de Apoio Psicossocial (CAPS) e as residências terapêuticas. O processo de execução da medida de segurança continua jurisdicionalizado, mas não será o juiz quem determinará o tratamento a ser dispensado ao paciente, pois é o médico o profissional habilitado a estabelecer a necessidade desta ou daquela terapia. Aliás, é a Lei 10.216 que exige laudo médico circunstanciado como pressuposto elementar para a internação psiquiátrica. A proteção jurisdicional é garantia constitucional do cidadão na esfera da execução penal e, na presidência do processo executivo, o juiz acompanhará o tratamento dispensado ao paciente e decidirá sobre eventuais excessos ou desvios, até final extinção da medida de segurança. (SILVA, 2010, p. 114).

Como ponto positivo do programa, o PAILI visa, em caráter principal, o tratamento. Desse modo, não mais se realiza laudo de exame pericial de cessação de periculosidade, apenas o laudo de avaliação psicossocial, em que se analisam as condições pessoais para a sua inserção social. Portanto, o maior objetivo do programa é o tratamento, o acompanhamento e a integração do paciente e de sua família à sociedade. Consideramos que o sucesso do programa se deu por ter sido iniciativa de um promotor de Justiça, que conseguiu mobilizar todo o sistema judicial criminal do Estado de Goiás.

\section{CONSIDERAÇÕES FINAIS}

O presente estudo se propôs a discutir se o processo de inserção social das pessoas com transtorno mental está funcionando e se os seus Direitos Humanos estão sendo respeitados, como prevê a Lei $n^{\circ} 10.216 / 01$, e se os ex-internos de hospitais psiquiátricos estão exercendo o convívio social, capaz de assegurar o bem-estar e de estimular o exercício pleno de seus direitos civis, políticos e de cidadania.

Constata-se, contudo, que há um silenciamento da Lei $\mathrm{n}^{\circ} 10.216 / 01$, na sua aplicabilidade pelo Judiciário. Seja por desinformação, desconhecimento da lei ou pelo fato de alguns magistrados e promotores de justiça não concordarem com determinados pontos inovadores no tratamento da doença mental que a lei visa disciplinar, principalmente no que tange à internação compulsória e aos dispositivos que recaem sobre a aplicação da Medida de Segurança. 
Com os dados apresentados, pode-se constatar que a Reforma Psiquiátrica no Brasil e, principalmente, no Estado do Piauí caminha a passos lentos. Exemplo disso é a atual situação de muitos pacientes do hospital psiquiátrico Areolino de Abreu, no Piauí, os quais se encontram plenamente capacitados a receberem alta médica e continuam residindo ali, por diversos motivos, que variam de burocracia à negativa de desinternação pelo Judiciário. Outro ponto observado foi que os funcionários do hospital, mesmo reconhecendo que ainda há muito a ser feito em âmbito de Reforma Psiquiátrica, ignoram e tentam camuflar, sempre que possível, a atual situação manicomial do Hospital Areolino de Abreu, o que a Lei $\mathrm{n}^{\circ}$ 10.216/01 proíbe.

Evidenciamos que, de todos os mecanismos extra-hospitalares trazidos pela Lei da Reforma Psiquiátrica, as residências terapêuticas, que são casas comuns, mantidas pelo governo e criadas para abrigar os pacientes oriundos de longas internações psiquiátricas e que perderam o laço com a família e com a comunidade, mesmo sendo insuficientes, consideramos como a estratégia mais efetiva, até o momento, para promover a desospitalização.

Com a produção deste estudo, tenta-se provar a teoria de que o modelo manicomial predominante antes da reforma, ao mesmo tempo em que libertou os portadores de doenças mentais das correntes, os aprisionou a um tratamento asilar, sob um regime total de isolamento. Procuramos mostrar, também, que a reforma em andamento está profundamente marcada pela ideia de defesa dos direitos humanos e de resgate da cidadania dos que carregam transtornos mentais, mas que ela ainda precisa percorrer um longo caminho até sua efetivação.

A Reforma Psiquiátrica, mais do que denunciar os manicômios como instituições asilares, propõe a construção de uma rede de serviços, além de estratégias territoriais e comunitárias, solidárias e libertárias. Objetiva-se deixar claro que o país e, em especial, o Piauí, não precisam mais de pacientes morando em hospitais, e que não existe meio termo, ou se defende uma política manicomial ou uma política antimanicomial. Compartilhamos então da proposta promovida pelo PAILI, ao considerarmos que é o único programa que de fato exerce a política antimanicomial ao doente mental infrator em nosso país.

Podemos dizer que, 14 anos depois, o embate ideológico entre Saúde, Direitos Humanos, Política Criminal e os modelos de atenção persiste até hoje, bem como a defesa dos princípios da lei permanece atual. Não obstante os preceitos contidos na Lei $n^{\circ} 10.216 / 2001$, verifica-se que permanece a ideia da exclusão e do confinamento perpétuos como "tratamento" para os portadores de transtorno mental. Exemplo disso é a grande população de moradores em hospitais psiquiátricos espalhados por todo Brasil. 
Faz-se necessária uma melhor fiscalização do Poder Judiciário e do Ministério Público e, principalmente, da Defensoria Pública aos hospitais psiquiátricos, na tentativa de evitar as atrocidades ainda comentidas e já retratadas em relatórios da Ordem dos Advogados do Brasil (OAB) e pelo Conselho Nacional de Justiça (CNJ). Nesse sentido, podemos concluir que, ao se tratar de Saúde Mental, é necessário tomar os Direitos Humanos como diretrizes e alicerces da argumentação.

\section{REFERÊNCIAS}

ARENDT, H. (1987). A condição humana. Rio de Janeiro: Editora Forense Universitária, 1987.

BARRETO, Djalma. O alienista, o louco e a lei. Petrópolis: Vozes, 1978.

BARROS, Fernanda Otoni de. Programa de Atenção Integral ao Paciente Judiciário PAI - PJ. Prêmio Innovare. Belo Horizonte, 2009. Disponível em:

$<$ http://www.premioinnovare.com.br/praticas/programa-de-atencao-integral-ao-pacientejudiciario-pai-pj/print/>. Acesso em: 2 abr. 2015.

BIRMAN, Joel. A cidadania tresloucada: notas introdutórias sobre a cidadania dos doentes mentais. In: BEZERRA, Benilson; AMARANTE, Paulo (Org.). Psiquiatria sem hospício: contribuições ao estudo da reforma psiquiátrica. Rio de Janeiro: Relume-Duramá, 1992, p. 7190 .

BOBBIO, N. A era dos direitos. Rio de Janeiro: Campus, 1992.

BRAGA, Vinícius Gil. Crítica à Execução Penal. As Medidas de Segurança à Luz do Estado Democrático de Direito: apontamentos à consecução de uma teoria agnóstica da Medida de Segurança. 2. ed. São Paulo: Lúmen Juris, 2007.

BRASIL. Constituição da República Federativa do Brasil de 1988. 35. ed. São Paulo: Saraiva, 2005.

Convenção Americana de Direitos Humanos, 1969. Disponível em:

<htp://www.pge.sp.gov.br/centrodeestudos/bibliotecavirtual/instrumentos/sanjose.htm>. Acesso em: 27 mai. 2015. 
. Decreto-Lei 2.848, de 7 de dezembro de 1940. Código Penal. Disponível em: <http://www.planalto.gov.br/ccivil_03/Decreto-Lei/Del2848compilado.htm>. Acesso em: 12 mar. 2015.

Decreto $n^{\circ}$ 82, de 18 de julho de 1841. (Fundando hum Hospital destinado privativamente para tratamento de Alienados, com a denominação de Hospício de Pedro Segundo). Brasília: Senado Federal. Disponível em: <http://www2.camara.leg.br/legin/fed/decret/1824-1899/decreto-82-18-julho-1841-561222publicacaooriginal-84711-pe.html>. Acesso em: 3 mai. 2015.

Lei $\mathbf{n}^{\mathbf{0}} \mathbf{1 0 . 2 1 6}$, de 6 de abril de 2001. Dispõe sobre a proteção e os direitos das pessoas portadoras de transtornos mentais e redireciona o modelo assistencial em saúde mental. Disponível em: <http://www.planalto.gov.br/ccivil_03/leis/leis_2001/110216.htm>. Acesso em: 10 abr. 2015.

Lei n ${ }^{\circ}$ 8.069. Estatuto da Criança e do Adolescente. Secretaria Especial dos Direitos Humanos. Ministério da Educação. Assessoria de Comunicação Social. Brasília: MEC, ACS, 2005.

Ministério da Saúde. IV Conferência Nacional de Saúde Mental - Intersetorial.

Relatório Final. Brasília, 2010. Disponível em: <www.saude.gov.br/saudemental>. Acesso em: 14 jun. 2015.

. Legislação em Saúde Mental 1990-2004. 5. ed. ampliada. Brasília: Editora MS, 2004. Disponível em: <www.saude.gov.br/saudemental>. Acesso em: 2 jun. 2015.

Portaria no 106, de 11 de Fevereiro de 2000. Institui os Serviços

Residenciais Terapêuticos. Disponível em:

<http://dtr2004.saude.gov.br/susdeaz/legislacao/arquivo/27_Portaria_106_de_11_02_2000.pd f>. Acesso em: 23 jul. 2015.

. Portaria SAS/MS no 189, de 19 de novembro de 1991. Aprova a inclusão de Grupos e Procedimentos da Tabela do SIH-SUS, na área de Saúde Mental (Hospitais Psiquiátricos). Disponível em:

<<http://bvsms.saude.gov.br/bvs/publicacoes/legislacao_mental.pdf>. Acesso em: 22 jul. 2015.

Portaria SNAS no 224, de 29 de janeiro de 1992. Institui as Normas para o Atendimento Ambulatorial (Sistema de Informação Ambulatorial do SUS). Disponível em: 〈http://bvsms.saude.gov.br/bvs/publicacoes/legislacao_mental.pdf $>$. Acesso em: 22 jul. 2015. 
Secretaria de Assistência à Saúde, Conselho Nacional de Saúde. III

Conferência Nacional de Saúde Mental. Caderno Informativo, 1. ed., série D, n. 14, Brasília - DF, 2001. ISBN B5 - 334-0437-9. . Disponível em:

<http://bvsms.saude.gov.br/bvs/publicacoes/0210IIIcnsm.pdf>. Acesso em: 12 mar. 2015.

Secretaria de Atenção à Saúde. DAPE. Coordenação Geral de Saúde Mental.

Reforma psiquiátrica e política de saúde mental no Brasil. Documento apresentado à

Conferência Regional de Reforma dos Serviços de Saúde Mental: 15 anos depois de Caracas. OPAS. Brasília, 2005. Disponível em:

<http://bvsms.saude.gov.br/bvs/publicacoes/Relatorio15_anos_Caracas.pdf>. Acesso em: 19 abr. 2015.

Senado Federal. Relatórios relacionados ao Projeto de Lei 08/91 (3.657/89, na

Câmara Federal). Brasília: Biblioteca do Senado, 2001.

BRITTO, Renata Corrêa. A internação psiquiátrica involuntária e a Lei 10.216/01:

Reflexões acerca da garantia de proteção aos direitos da pessoa com transtorno mental. 2004. 210 f. Dissertação (Mestrado em Saúde Pública)- Escola Nacional de Saúde Pública do Rio de Janeiro, Rio de Janeiro, 2004.

CASTORIADIS, C. As Encruzilhadas do Labirinto 2: Os Domínios do Homem. Rio de Janeiro: Paz e Terra, 1986.

CORTE INTERAMERICANA DE DIREITOS HUMANOS. Caso Ximenes Lopes versus

Brasil. Sentença de 4 de julho de 2006. (Mérito, Reparações e Custas), 2006. Disponível em: <www.corteidh.or.cr/docs/casos/articulos/seriec_149_por.pdf>. Acesso em: 5 jul. 2015.

DELGADO, Paulo. O Espírito da Lei ${ }^{\circ}$ 10. 216/01. Revista Jurídica Consulex, ano XIV, n. 320, p. 24-25, 15 mai. 2010.

FERLA, Luis Antônio Coelho. Feios, sujos e malvados sob medida: do crime ao trabalho, a utopia médica do biodeterminismo em São Paulo (1920-1945). 2005. 379 f. Tese

(Doutorado)- Departamento de História. Faculdade de Filosofia, Letras e Ciências Humanas da Universidade de São Paulo, São Paulo, 2005.

FOUCAULT, Michel. História da loucura na idade clássica. 8. ed. São Paulo: Perspectiva, 2004.

GIANESINI, Huilla Mariana Salviano. A Saúde Mental no Âmbito Jurídico: a árdua Luta Antimanicomial no Brasil. FADIVA. Varginha, 2011. Disponível em:

<http://www.fadiva.edu.br/Documentos/publicacoes/2011/04.pdf>. Acesso em: 22 abr. 2015. GOFFMAN, Erving. Estigma. Manicômios, prisões e convênios. São Paulo: Perspectiva, 2007. 
JACOBINA, Paulo Vasconcelos. Direito Penal da Loucura. Brasília: ESMPU, 2008.

LIMA, Aluísio Ferreira de. Os movimentos progressivos-regressivos da reforma Psiquiátrica Antimanicomial no Brasil: uma análise da saúde mental na perspectiva da psicologia social crítica. Revista Salud \& Sociedad, Antofagasta, v. 1, n. 3, p. 165-177, set./dez. 2010.

Disponível em:

<regressivos_da_reforma_psiquiátrica_antimanicomial_no_Brasil_uma_análise_da_saúde_m ental_na_perspectiva_da_Psicologia_Social_Crítica>. Acesso em: 15 jun. 2015.

MACEDO, Camila Freire. A evolução das políticas de saúde mental e da legislação psiquiátrica no Brasil. Jus Navigandi. Teresina, 2006. Disponível em:

<http://jus.com.br/revista/texto/8246>. Acesso em: 29 jul. 2015.

MARTINS, Flademir Jerônimo Belinati. Dignidade da pessoa humana: princípio constitucional fundamental. Curitiba: Juruá, 2003.

QUEIROZ, Carlos Alberto Marchi de. Resumo Jurídico de Direitos Humanos. 3. ed., v. 22. São Paulo: Quartier Latin, 2006.

SILVA, Haroldo Caetano da. Reforma psiquiátrica nas medidas de segurança: a experiência goiana do Paili. Revista Brasileira de Crescimento e Desenvolvimento Humano, São Paulo, v. 20, n. 1, p. 112-115, abr. 2010.

SOUTO, Ronya Soares de Brito e. Crítica a Execução Penal. Medidas de Segurança: Da criminalização da Doença aos Limites do Poder de Punir. 2. ed. São Paulo: Lúmen Juris, 2007.

SZASZ, Thomas. Ideologia e doença mental. 2. ed. Rio de Janeiro: Zahar Editores, 1978.

TENÓRIO, Fernando. A psicanálise e a clínica da reforma psiquiátrica. Rio de Janeiro: Rios Ambiciosos, 2001. 